\title{
The Effect of Tricyclic Antidepressants on Cortex- and Amygdala-Kindled Seizures in the Rat
}

\author{
R. Yacobi and W.M. Burnham
}

\begin{abstract}
The anticonvulsant effects of amitriptyline, imipramine, nortriptyline and desipramine were tested against focal and generalized seizures, triggered from either the amygdala or the cortex in fully kindled rats. Tests were administered on a 72- or a 24-hour schedule. Significant seizure suppression was achieved with only one drug, amitriptyline, and it occurred only at toxic or near-toxic doses. The differential, low-dose suppression of amygdala-kindled seizures, reported in earlier studies, was not seen in the present experiments. It may occur only in the short-interval test paradigms used by previous experimenters.
\end{abstract}

RÉSUMÉ: Effet des antidépresseurs tricycliques sur les convulsions naissant dans le cortex et l'amygdale. L'effet anticonvulsivant de l'amitriptyline, de l'imipramine, de la nortriptyline et de la désipramine sur les convulsions focales et généralisées, déclenchées soit de l'amygdale ou du cortex chez des rats stimulés au maximum, a été évalué. Les épreuves étaient administrées en deux horaires, soit sur 72 ou sur 24 heures. Une suppression significative des crises a été obtenue avec seulement un produit, l'amitriptyline, et cette suppression n'a été obtenue qu'à des doses toxiques ou presque. La suppression sélective, à doses faibles, des crises naissant dans l'amygdale rapportee dans des études antérieures n'a pas été reproduite dans la présente étude. Il se peut que cette suppression ne survienne que dans le paradigme d'épreuves de courte durée utilsées dans ces études.

The kindling preparation is an animal model of epilepsy in which secondarily generalized seizures develop as the result of repeated, low-intensity, focal brain stimulation.1.2.3 A large number of pharmacological studies have now been performed on kindled subjects, and it has been suggested that the model may play a useful role in drug development.4,5.6 The amygdalakindled seizure, in particular, has been proposed as a model for human complex partial seizures. ${ }^{7,8}$ There is at present no standard model for this widespread and drug-resistant type of attack.

An interesting feature of amygdala-kindled convulsions is that they have been reported to be differentially responsive to suppression by tricyclic antidepressant drugs. This effect which does not occur with other drug classes - was initially reported by Babington and Wedeking, ${ }^{9}$ who worked with female Holtzman rats and a short-interval test paradigm (seizures were elicited at 15-minute intervals). These investigators found that three tricyclics - amitriptyline, nortriptyline and imipramine all suppressed amygdala-kindled convulsions with $\mathrm{ED}_{50}$ 's in the low, non-toxic range of $5-15 \mathrm{mg} / \mathrm{kg}$. The same drugs had considerably less effect on cortex-triggered convulsions, where $\mathrm{ED}_{50}$ 's were 3-5 times higher and sometimes in the toxic range.

Similar results have been reported by subsequent workers, using somewhat different test paradigms. Knobloch et al., 10 working with male Wistar rats and a 30-60 minute inter-seizure interval, found amygdala $\mathrm{ED}_{50}$ 's (calculated from their figures) of approximately $20 \mathrm{mg} / \mathrm{kg}$ for imipramine and $30 \mathrm{mg} / \mathrm{kg}$ for amitriptyline. Cortical $\mathrm{ED}_{50}$ 's were approximately $40 \mathrm{mg} / \mathrm{kg}$ and $50 \mathrm{mg} / \mathrm{kg}$ for the same drugs. Burnham et al., 11 working in male Royal Victoria hooded rats with a 24-hour inter-seizure interval, obtained an $E D_{50}$ of $35 \mathrm{mg} / \mathrm{kg}$ for amitriptyline. The $E D_{50}$ for cortex-triggered convulsions was higher, but could not be determined exactly due to the toxicity (ataxia and convulsions) associated with high-dose amitriptyline. It is interesting to note that in both Knobloch's and Burnham's experiments, $E_{50}$ 's for the suppression of amygdala-triggered seizures were higher than they had been in Babington and Wedeking's experiments. In

From the Department of Pharmacology, University of Toronto, Toronto

Received August 28, 1990. Accepted November 15, 1990

Reprint requests to: Dr. W.M. Burnham, Department of Pharmacology, M.S.B., University of Toronto, Toronto, Ontario, Canada M5S IA8 
both cases, however, $E_{50}$ 's for the suppression of amygdalatriggered convulsions were lower than $\mathrm{ED}_{50}$ 's for suppression of convulsions triggered from the cortex.

The differential, low-dose response of amygdala-kindled seizures to tricyclics seems to suggest that these drugs might be of use in the treatment of complex partial epilepsy. The present study, therefore, was designed to confirm and extend the data previously obtained in the paradigm of Burnham et al." This paradigm - which monitors focal electrographic as well as generalized convulsive seizures - has been used in anticonvulsant drug testing, and has produced data which are in good agreement with clinical drug responses. ${ }^{7,12}$ Four tricyclics were tested: amitriptyline (previously tested in 1980), imipramine, nortriptyline and desipramine. Procedures resembled those of Burnham et al.," except that tests were initially administered at a 72 - rather than a 24-hour interval. This change was made to allow subjects to recover from the toxicity associated with high tricyclic doses.

Following the unexpected results of Experiment 1, amitriptyline - the strongest of the drugs - was re-tested using a 24 hour inter-trial interval (Experiment 2). The amitriptyline data from both experiments, originally subjected to "quantal" scoring (as in Burnham et al."), were also re-scored in a "graded" fashion to allow for better comparison with the data of Babington and Wedeking ${ }^{9}$ and Knobloch et al. ${ }^{10}$

\section{Materials AND Methods}

\section{Subjects, Surgery and Kindling}

Male rats of the Royal Victoria hooded strain (200-250 grams) were obtained from Charles River Canada (La Prairie, Quebec). In preparation for kindling, each subject was implanted with a single bipolar stimulating-recording electrode aimed either at the basolateral amygdala or the anterior neocortex. Conventional stereotaxic techniques and pentobarbital-chloral hydrate anesthesia were employed for surgery, plus the following coordinates: 1) cortex: anterior $-2.5 \mathrm{~mm}$ (bregma); lateral $3.0 \mathrm{~mm}$; down - $2.5 \mathrm{~mm}$ (skull surface); 2) amygdala: posterior $1.0 \mathrm{~mm}$ (bregma); lateral $-4.5 \mathrm{~mm}$; down $-8.0 \mathrm{~mm}$ (skull surface). The incisor bar was set at $+5.0 \mathrm{~mm}$.

Following a two-week period for post-operative recovery and handling, all rats were subjected to daily kindling stimulation (5 days a week) until 30 generalized convulsions had been elicited. The following stimulation parameters were employed: train duration - 1 second; pulse duration - $1 \mathrm{msec}$; pulse configuration - biphasic square wave; pulse frequency - $60 \mathrm{~Hz}$. Intensities were set at a standard level of $400 \mu \mathrm{a}$ (peak to peak) for the amygdala-kindled subjects and $800 \mu$ a (peak to peak) for the cortex-kindled subjects. The higher cortical intensity was employed because of the higher afterdischarge thresholds found in the neocortex. 13 "Focal" seizures were scored as being present whenever epileptiform spiking was detected in the electroencephalogram immediately following stimulation. "Generalized" seizures were scored as being present whenever epileptiform spiking lasted 30 seconds or more, and was accompanied by Racine's stage 3, 4 or 5 convulsions. ${ }^{2}$ Animals that did not display focal seizures by the 5 th daily stimulation were excluded from the study, as were amygdala subjects that failed to develop generalized seizures by the 20th stimulation and cor- tical subjects that failed to develop generalized seizures by the 80 th stimulation. Before drug testing, cortical and amygdaloid subjects were paired on the basis of the number of stimulations required to reach criterion. Each pair was tested in tandem thereafter.

\section{Drugs and Drug Administration}

The following drugs were used: amitriptyline hydrochloride (Elavil $^{\mathrm{R}}$, Merck Sharp and Dohme); imipramine hydrochloride (Sigma Chemical Co.); nortriptyline hydrochloride (Aventy $\mathbf{l}^{R}$, Eli Lilly); and desipramine hydrochloride (Pertofrane ${ }^{R}$, CibaGeigy). Amitriptyline was obtained in pre-mixed injectable form, while the other three drugs were obtained in pure substance form. All drug solutions were mixed (or diluted) fresh daily. Injections were given i.p., in a volume of $4 \mathrm{ml} / \mathrm{kg}$. (This large volume was required due to the relative insolubility of the demethylated drugs). The vehicle for drug injection was either a $4.4 \%$ dextrose solution (for amitriptyline), or physiological saline (for nortriptyline, imipramine and desipramine). Each drug was administered in 4 or 5 doses, doses being chosen to range from sub-therapeutic to toxic levels. Toxicity was defined as the appearance of ataxia or spontaneous convulsions. Ataxia was scored according to the scheme of Desmedt et al. 14 During drug testing, injections preceded kindling stimulations by an interval of 30 minutes.

\section{Procedures for Drug Testing}

Experiment 1: Saline injections were first administered for three "baseline" weeks on the 72-hour schedule subsequently to be used for drug tests. Any subject pair that failed to display stable convulsions during this period was excluded from further testing. Drug testing was then begun for the 10 pairs of subjects that had reached criterion. Drug tests resembled regular kindling trials, except that the kindling stimulation was preceded by a drug injection. Each pair of subjects received all drugs and all doses, administered in a randomized order.

Experiment 2: In experiment 2, the same procedures were used, except that only amitriptyline was tested, and that stabilization and testing were done on a 24-hour schedule. Six pairs of subjects were used.

\section{Data Collection and Analysis}

Electroencephalographic recordings were taken from the focus for 20 seconds before and two minutes after each stimulation. Durations of electrographic discharge and convulsive behavior were recorded, and the severity of the convulsions (if any) was rated by Racine's seizure stages. ${ }^{2}$ When high drug doses induced spontaneous seizures before stimulation, the test session was cancelled, and the data were excluded from analysis.

Two different methods were used for scoring the data: 1) Quantal Method: "Quantal" scoring of both electrographic and behavioral seizures was done according to the method of Burnham et al." This involves scoring the presence or absence of: a) generalized convulsive behavior (defined above); and b) electrographic afterdischarge at the focus. 2) Graded Method: "Graded" scoring of convulsive behavior (only) was done according to the method of Babington and Wedeking. ${ }^{9}$ In this 
method, the duration of post-drug convulsive behavior is expressed as a percent of pre-drug "baseline" duration. In the present study, "baseline" was considered to be the mean duration of the seizures that had occurred on the saline days.

Log dose-response curves were constructed for both the "quantal" and the "graded" data, and the significance of differences in slope and elevation was assessed by analysis of covariance.

\section{Histological Examination}

At the end of the study, animals were perfused under pentobarbital anesthesia with saline and 10\% formalin solution. Frozen sections of the brains were taken and stained with thionine. Histological examination confirmed that all electrodes had been in the intended structures.

\section{Results}

Experiment 1 Figure 1 presents quantal dose-response curves for the suppression of electrographic and generalized convulsive seizures triggered from either the amygdala or the cortex on a 72-hour schedule. As indicated, little seizure suppression was observed with any drug at doses below $20 \mathrm{mg} / \mathrm{kg}$. At higher doses, all of the drugs showed some effect, but only amitriptyline achieved a 50\% level of seizure suppression, and that was achieved only for generalized convulsions in cortextriggered subjects. Statistical comparisons (analysis or covariance) revealed no significant differences between the suppression of focal and generalized seizures, and only one significant difference between the suppression or cortex-and amygdalatriggered convulsions: amitriptyline was significantly more potent against cortex-triggered convulsions $(\mathrm{p}<0.05)$.

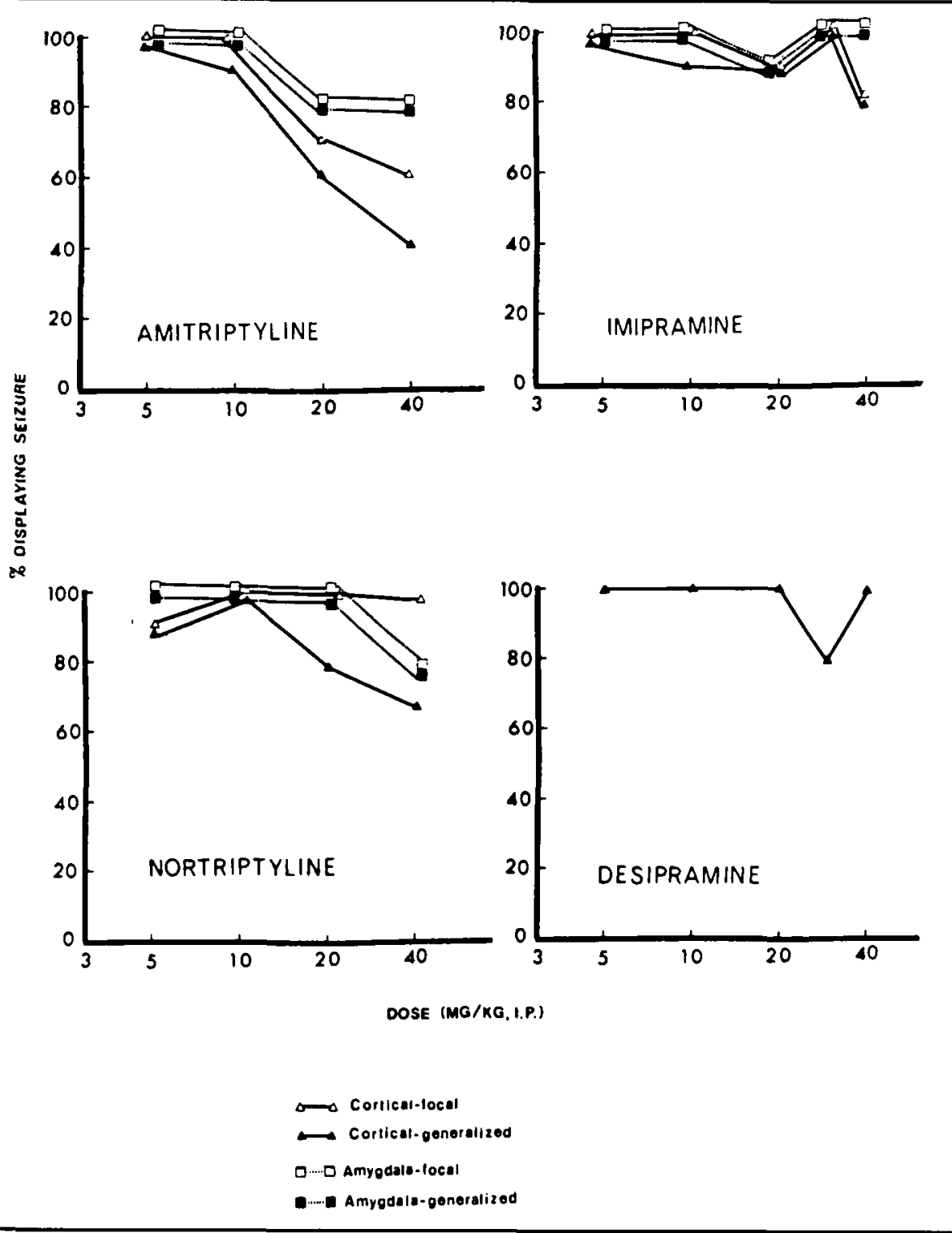

Figure I - Quantal dose-response curves for the suppression of kindled seizures by amitriptyline, nortriptyline, imipramine and desipramine. (Note: At all doses of desipramine, $100 \%$ of cortex-implanted subjects displayed focal seizures, and $100 \%$ of amygdalaimplanted subjects displayed both focal and generalized seizures.) 
Ataxia (Desmedt's Stage 2 or higher) was observed above 20 $\mathrm{mg} / \mathrm{kg}$ with all four drugs. Spontaneous convulsions began to occur at $30 \mathrm{mg} / \mathrm{kg}$ in the cases of imipramine and desipramine, and at $40 \mathrm{mg} / \mathrm{kg}$ in the cases of amitriptyline and nortriptyline.

Experiment 2 Table 1 presents $\mathrm{ED}_{50}$ 's for amitriptyline suppression of cortex- and amygdala-triggered convulsions on a 24hour schedule. Seventy-two hour $\mathrm{ED}_{50}$ 's from Experiment 1 are also presented, and both sets of data have been subjected to "graded" as well as "quantal" analysis. As indicated, cortical $E D_{50}$ 's were not much affected by the change to a 24-hour schedule. Amygdala $\mathrm{ED}_{50}$ 's, however, were lower at 24 than at 72 hours. The significant difference between cortex- and amygdala-triggered convulsions was no longer seen, and, when graded scoring was used, the amygdaloid $\mathrm{ED}_{50}$ was actually lower than the cortical $\mathrm{ED}_{50}$.

\section{Discussion}

The present study was designed to confirm and extend past reports concerning the differential sensitivity of amygdala-kindled seizures to suppression by tricyclic antidepressants. Contrary to expectation, no differential amygdaloid sensitivity was observed. In Experiment 1, none of the drugs proved to be very potent, and amitriptyline - the only drug which achieved an $\mathrm{ED}_{50}$ - was more potent against cortex-triggered convulsions. In Experiment 2, when amitriptyline was re-tested on a 24-hour schedule, there was no significant difference between the two groups.

Table 1: ED $_{\mathbf{5 0}}$ 's For Suppression of Generalized Convulsions by Amitriptyline*

\begin{tabular}{|c|c|c|c|c|}
\hline & \multicolumn{2}{|c|}{$E D_{50}(\mathrm{mg} / \mathrm{kg})$} & \multicolumn{2}{|c|}{$\begin{array}{l}\text { Statistical Comparisons** } \\
\text { (cortex versus amygdala) }\end{array}$} \\
\hline & $\begin{array}{l}\text { Cotex- } \\
\text { triggered }\end{array}$ & $\begin{array}{l}\text { Amygdala- } \\
\text { triggered }\end{array}$ & Slope & Elevation \\
\hline \multicolumn{5}{|c|}{ QUANTAL SCORING *** } \\
\hline $\begin{array}{l}\text { 72-hour } \\
\text { schedule }\end{array}$ & 30 & —**** & n.s. & $<0.05$ \\
\hline $\begin{array}{l}\text { 24-hour } \\
\text { schedule }\end{array}$ & 39 & — $^{* * * *}$ & n.s. & n.s. \\
\hline \multicolumn{5}{|c|}{ GRADED SCORING ***** } \\
\hline $\begin{array}{l}\text { 72-hour } \\
\text { schedule }\end{array}$ & 20 & 34 & n.s. & n.s. \\
\hline $\begin{array}{l}\text { 24-hour } \\
\text { schedule }\end{array}$ & 24 & 17 & n.s. & n.s. \\
\hline
\end{tabular}

* Significant seizure suppression was achieved only against generalized convulsions.

** Comparison of dose-response curves for cortex- and amygdala-kindled subjects (analysis of covariance).

*** Convulsion scored as "present" or "absent" (as in Ref. 11).

$* * * * \quad 50 \%$ suppression never achieved, even at toxic doses.

$* * * * *$ Duration of convulsion expressed as a percent of baseline (as in Ref. 9).
Why do these results differ from the results reported by previous investigators? A comparison of Experiments $I$ and 2 suggests a possible hypothesis: that amygdala-triggered (but not cortex-triggered) seizures are more susceptible to tricyclic suppression when test trials are spaced closely together. This hypothesis would fit all of the available data: $E_{50}$ 's for cortextriggered convulsions have been high in all of the published experiments, whereas amygdala-triggered $\mathrm{ED}_{50}$ 's have been reported as higher than cortical $E D_{50}$ 's on a 72 -hour schedule (our data), about the same on a 24-hour schedule (our data), $50 \%$ lower on a 30 -minute schedule, 10 and about 5 times lower on a 15-minute schedule. ${ }^{9}$ Such schedule-dependent effects might result from an interaction between tricyclics and post-ictal inhibition, which is highest immediately after a seizure, and which may last as long as 24 hours. ${ }^{15}$ A recent report by McIntyre et al. ${ }^{16}$ suggests that post-ictal inhibition is mediated by noradrenaline, and tricyclics are known to enhance noradrenergic activity. ${ }^{17}$

Future work will be required to investigate possible interactions between tricyclics effects and short-interval schedules. The present data, however, indicate that the tricyclics are only weakly active against kindled seizures when tested on a spaced-interval schedule, and that there is no differential suppression of anygdala-triggered convulsions. These results, obtained in a paradigm with good clinical validity, suggest that tricyclics would be of little use in the control of complex partial attacks. They further suggest that the data derived from tests involving kindled seizures may differ when different test paradigms are employed. In particular, it seems possible that tests involving closely spaced trials may give different results than tests utilizing longer inter-test intervals.

\section{ACKNOWLEDGEMENTS}

Supported by grant MA 5611 from the Medical Research Council of Canada to Dr. W.M. Burnham. The authors would like to thank Dr. Georgia Cottrell for critical reading of the manuscript, and Merck, Sharp and Dohme Canada, Eli Lilly Canada, Inc., and Geigy Pharmaceuticals for their gifts of (respectively) amitriptyline hydrochloride, nortriptyline hydrochloride, and desipramine hydrochloride. Dr. Yacobi's present address is 57 Tyrrel Avenue, Toronto, Ontario M6G $2 \mathrm{G} 2$.

\section{REFERENCES}

1. Goddard GV, McIntrye, DC and Leech CK. A permanent change in brain function resulting from daily electrical stimulation. Exp Neurol 1969; 25: 295-330.

2. Racine RJ. Modification of seizure activity by electrical stimulation: II. Motor seizures. EEG Clin Neurophysiol 1982: 32: 281 294.

3. Bumham WM. Primary and "transfer" seizure development in the kindled rat. Can J Neurol Sci 1975; 2: 417-428.

4. Wada J. Pharmacological prophylaxis in the kindling model of epilepsy. Arch Neurol 1977; 34: 389-395.

5. Trabka W, Trabka E and Trabka J. Kindled seizures: anticonvulsanı drugs and agents. Pol J Pharmacol Pharm 1988; 40: 87-115.

6. Schmutz $M$ and Klebs K. Kindling and antiepileptic drugs. In: Bolwig G, Trimble MR, eds. The Cinical Relevance of Kindling, John Wiley \& Sons Lid. 1989.

7. Albright PS and Burnham WM. Development of a new pharmacological seizure model: Effects of anticonvulsant or cortical- and amygdala-kindled seizures in the rat. Epilepsia 1980; 21: 681689.

8. Loscher W, Jackel R and Czuczwar SJ. Is amygdala kindling in rats a model for drug-resistant partial epilepsy? Exp Neurol 1986; 93: $211-226$. 
9. Babington RG and Wedeking PW. The pharmacology of seizures induced by sensitization with low intensity brain stimulation. Pharmacol Biochem Behav 1973; 1: 461-467.

10. Knobloch LC, Goldstein JM and Malick JB. Effects of acute and subacute antidepressant treatment on kindled seizures in rats. Pharm Biochem and Behav 1982; 17: 461-465.

11. Burnham WM, Lychaz B, Avila J, et al. Differential pharmacological response of cortex- and amygdala-kindled seizures. In: Girgis $M$ and Kiloh L, eds. Limbic Epilepsy and the Dyscontrol Syndrome 1980; 161-170.

12. Racine RJ and Burnham WM. The kindling model. In: Schwartzkroin PA and Wheal $\mathrm{H}$, eds. Electrophysiology of Epilepsy. New York: Raven Press 1984; 153-171.

13. Burnham WM. Cortical and limbic kindling: similarities and differences. In: Livingston KE and Hornykiewicz O, eds. Limbic Mechanisms: The Continuing Evolution of the Limbic System Concept. New York: Plenum Press 1978; 507-519.
14. Desmedt LKG, Niemegeers CJE, Lewi PJ, et al. Antagonism of maximal metrazol seizures in rats and its relevance to an experimental classificiation of antiepileptic drugs. Anzneim Forsch 1975; 26: 1592-1602.

15. Sainsbury RS, Bland BH and Buchan DH. Electrically induced seizure activity in the hippocampus: time course for postseizure inhibition of subsequent kindled seizures. Behav Biol 1978; 22: 479-488.

16. McIntyre DC, Rajala J, and Edson N. Suppression of amygdala kindling with short interstimulus intervals: effect of norepinephrine depletion. Exp Neurol 1987; 95: 391-402.

17. Baldessarini RJ. Drugs and the Treatment of Psychiatric Disorders. In: Gilman AG, Goodman LS, Rall TW and Murad F, eds. The Pharmacological Basis of Therapeutics. New York: MacMillan Publishing Co. 1985; 19: 387-445. 